\title{
Geomagnetic Field Variations in the Equatorial Electrojet Sector
}

\author{
Freire, L. *(UERJ) Laranja, S. R. (UFF) and Benyosef, L. (ON)
}

Copyright 2016, SBGf - Sociedade Brasileira de Geofísica

Este texto foi preparado para a apresentação no VII Simpósio Brasileiro de Geofísica, Ouro Preto, 25 a 27 de outubro de 2016. Seu conteúdo foi revisado pelo Comitê Técnico do VII SimBGf, mas não necessariamente representa a opinião da SBGf ou de seus associados. É proibida a reprodução total ou parcial deste material para propósitos comerciais sem prévia autorização da SBGf.

\section{Abstract}

The purpose of this paper is to analyze the Sq variations in the $\mathrm{H}$ and $\mathrm{Z}$ geomagnetic field elements at five different locations along different longitudes and also discuss the mechanisms responsible for the observed variations. The results of this study confirm that the morphology of the curves obtained for $\mathrm{H}$ and $\mathrm{Z}$ might be interpreted to be due to the Equatorial Electrojet (EEJ). Moreover, diurnal variations curves of TTB, CAA, HUA and AAE indicated the presence of MCEJ.

\section{Introduction}

In equatorial regions the normal quiet day (Sq) variation of the geomagnetic field shows a strong enhancement which is attributed to the Equatorial Electrojet (EEJ). The EEJ is a narrow belt of intense electric current in the ionosphere confined to about $\pm 3^{2}$ at the dip equator (Chapman, 1951a, and Adimula, et al, 2011). In the dayside equatorial ionosphere, currents driven by tidal wind through the dynamo mechanism cause an accumulation of charges, which are positive at dawn and negative at dusk terminators, and this result in an eastward electric field, along the magnetic equator. The cross fields of this electric field and northward magnetic field results in an eastward Pedersen current and downward Hall current. The Pedersen current flows dominantly at about $130-\mathrm{km}$ altitude in response to the peak Pedersen there. The downward Hall current leads to an accumulation of charges at the upper and lower edges of the dynamo layer, which results in the formation of an upward polarized electric field. This vertical polarization electric field induces a strong eastward Hall current. This Hall current flows and peaks around $110-\mathrm{km}$ altitude in response to the peak Hall conductivity there (Hamid, et al, 2014).

Gouin (1962) noticed the interesting aspect of the reversal in direction of the normal northward directed field of the horizontal component around midday hours at the equatorial station Addis Ababa. Gouin and Mayaud (1967) explained these negative depressions of the regular $\mathrm{H}$-field to be effect of a westward flow of electrojet current and named this phenomenon as "Equatorial Counter Electrojet" (CEJ). Similar occurrences in the diurnal variation in the $\mathrm{H}$ component were observed at other equatorial stations (S. Alex and S. Mukherjee, 2001).

The aim of this paper therefore is to analyze the Sq variations in the $\mathrm{H}$ and $\mathrm{Z}$ geomagnetic field elements at five different locations along different longitudes using an empirical model constructed by Yamazaki et al. (2011).
Also, we discuss the mechanisms responsible for the observed variations.

In this paper we discuss the morphology of the EEJ in the equatorial region based on data during the period of November $15^{\text {th }}, 2008$ to November $28^{\text {th }}, 2008$ from 4 permanent observatories (TTB, HUA, MBO and AAE) and 1 temporary station (CAA). Only the quiet condition was examined. Figure 1 shows the geographic distribution of these stations. Table 1 gives the coordinates of all stations.

Table 1 - Geographic coordinates of the stations used

\begin{tabular}{|c|c|c|c|c|}
\hline & \multicolumn{2}{|c|}{ Station } & \multicolumn{2}{|c|}{ Geographic } \\
\hline Name & $\overline{\mathrm{LT}}$ & Code & Latitude $(\stackrel{\circ}{\circ})$ & Longitude $\left({ }^{\circ}\right)$ \\
\hline Tatuoca & UT-3 & TTB & $\begin{array}{l}1^{\circ} 12^{\prime} 00^{\prime \prime} \\
\text { South }\end{array}$ & $\begin{array}{c}48^{\circ} 30^{\prime} 00^{\prime \prime} \\
\text { West }\end{array}$ \\
\hline $\begin{array}{c}\text { Cachoeira } \\
\text { do Arari }\end{array}$ & UT-3 & CAA & $\begin{array}{c}1^{\circ} 0 \text { ' } 16^{\prime \prime} \\
\text { South }\end{array}$ & $\begin{array}{c}48^{\circ} 57^{\prime} 27^{\prime \prime} \\
\text { West }\end{array}$ \\
\hline Huancayo & UT-5 & HUA & $\begin{array}{l}12^{\circ} 3^{\prime} 54^{\prime \prime} \\
\text { South }\end{array}$ & $\begin{array}{c}75^{\circ} 12^{\prime} 17^{\prime} \\
\text { West }\end{array}$ \\
\hline Mbour & UT & $\mathrm{MBO}$ & $\begin{array}{c}14^{\circ} 25^{\prime} 00^{\prime \prime} \\
\text { North }\end{array}$ & $\begin{array}{c}16^{\circ} 58^{\prime} 00^{\prime \prime} \\
\text { West }\end{array}$ \\
\hline Addis Ababa & UT+3 & AAE & $\begin{array}{l}9^{\circ} 1^{\prime} 48^{\prime \prime} \\
\text { North }\end{array}$ & $\begin{array}{c}38^{\circ} 44^{\prime} 24^{\prime \prime} \\
\text { East }\end{array}$ \\
\hline
\end{tabular}

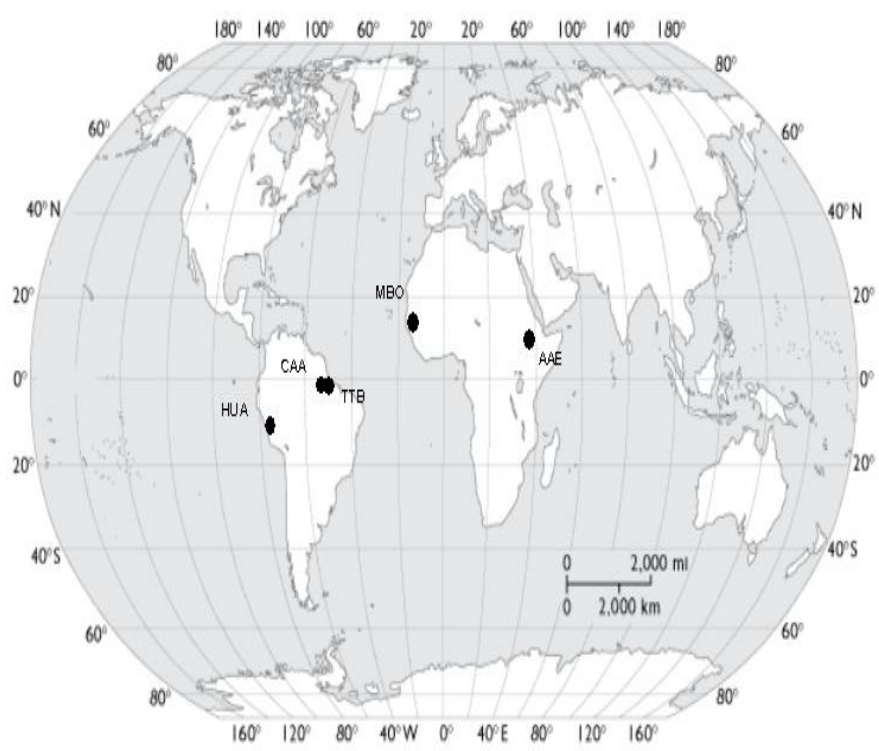

Figure 1- The geographic location of the stations. 


\section{Method}

The analysis started with selection of the magnetically quiet days. The five quietest days used were those which the greatest value of the planetary geomagnetic disturbance index $\mathrm{Kp}$ is less than or equal to $2+$. The $\mathrm{Kp}$ index is provided by International Service of Geomagnetic Indices. The auroral electrojet index AE is below 200nT what suggests that effects of substorm-related disturbances are not significant.

From the data that has one-minute resolution, one-hour median values were derived. A quiet level baseline was defined for each day as the mean of six nighttime values (0000, 0100, 0200, 2200, 2300 and $2400 \mathrm{UT})$. dH, and dZ were computed by subtracting the base line from $\mathrm{H}$, and $\mathrm{Z}$ geomagnetic components (Yamazaki, Y., et al., 2011).

In this paper, "quiet daily geomagnetic field variation" means the variation defined by equation (1) for geomagnetically quiet conditions.

$d H(U T)=H(U T)-\frac{H(0)+H(1)+H(2)+H(22)+H(23)+H(24)}{6}(1)$
The quiet geomagnetic field variation $(\mathrm{dZ})$ was computed by the same equation above.

The usage of these baselines are based on the assumption that the nighttime ionospheric currents are too small to be significant during geomagnetically quiet conditions. This assumption is widely accepted because the conducting $\mathrm{E}$ region of the ionosphere largely disappears at night hours except at the auroral latitudes (ap. Yamazaki, Y., et al., 2011).

\section{Results and discussion}

The solar quiet daily amplitude for all stations is shown in Figure 2. This shows the existence of large day to day variability of the amplitude for equatorial stations. For example, on November 18, 2008 the maximum amplitudes for the stations vary from about $92 \mathrm{nT}$ to about $33 \mathrm{nT}$, a range of $59 \mathrm{nT}$. This is in agreement with the work of Adimula et al. (2011). It is evident that the amplitude $\mathrm{dH}$ in HUA is higher than that in all other stations. This is explained by the fact that HUA (0.4을 latitude) is located within the equatorial electrojet zone. According to Obiekezie (2013) these high amplitudes could be as a result of the influence of the Equatorial electrojet current.

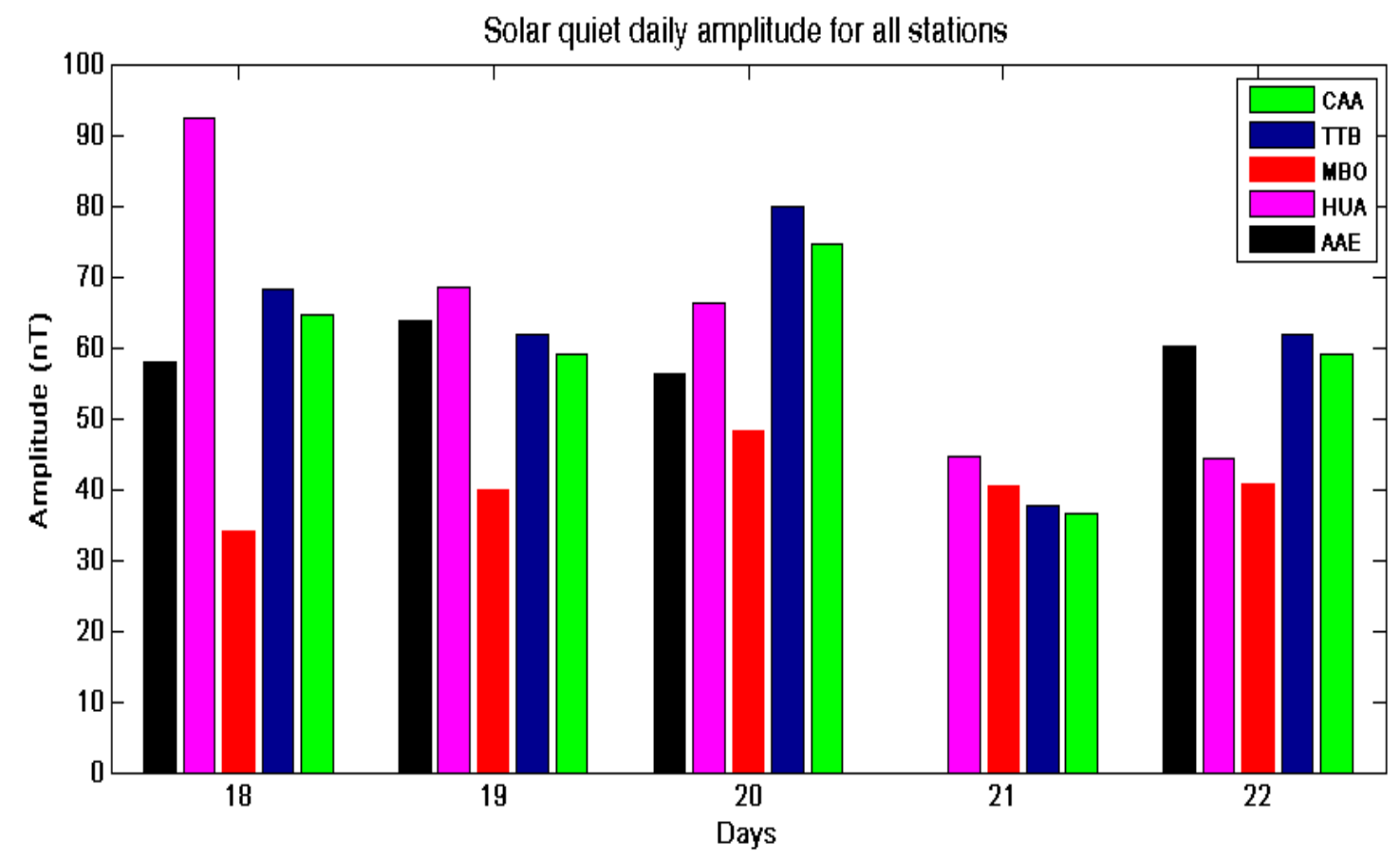

Figure 2 - Solar quiet daily amplitude for all stations. 
The quiet daily variations of $\mathrm{H}$ component for the quietest days are shown in Figure 3. According to Obiekezie (2012) the $\mathrm{H}$ component regularly increases from the night level, reaches its maximum around noon, and then regularly decreases down to its night level. This pattern was observed in almost all stations used for his study. The $\mathrm{Sq}$ variation peaks during the daytime are mostly around noon within the range of $1000 \mathrm{LT}$ to $1400 \mathrm{LT}$ for all days used in this analysis. The daytime magnitude of the solar daily variation in the magnetic field is greater than the night-time magnitudes for all stations which are in agreement with previously works (Adimula, 2011, Obiekezie 2012 and Rabiu, 2007). It can be attributed to the variability of the ionospheric processes and physical structures such as conductivity and winds structures (Rabiu et al., 2007).

Diurnal variation curves of TTB, CAA and HUA for November 18th, 19th and 20th shown in Figure 3, indicate the presence of MCEJ around 0700LT and 0900LT lasting for about 2 to 3 hours at both locations. The morphology of the curve for AAE on the $18^{\text {th }}$ of November shows a gradual decrease in the morning which indicate the presence of MCEJ around 0700LT lasting for 2 hours. However, there is not any evidence of MCEJ at MBO during the period of this analysis. This occurrence does not seem to alter the trend of diurnal variation at any of the stations.
On November $21^{\text {st }}$, TTB and CAA had two maxima occurring in the $\mathrm{H}$ component, the fist around 1500UT and the other around 1900UT. The same behavior can be observed at HUA with peaks around 1700UT and the other around 2200UT. According to Obiekezie this variability could be attributed to the presence of a reverse current flowing in the region.

A phase difference is observed between $M B O, A A E$, CAA, TTB and HUA. This phase shift may be attributed to the differences in their locations. The curves present the same shape for all stations used for this study.

The diurnal variation of the $Z$ components exhibits an opposite sign from the northern side of the dip equator to the southern side. For the northern stations is negative and for the southern stations is positive (Obiezekie, 2012). This pattern was observed for all stations used in the present work. However, TTB, CAA and MBO displayed more variation in $Z$ than $A A E$. The $d Z$ variation at TTB, CAA and MBO decrease from morning, reach a minimum at about local noon, and a rise towards sunset period.
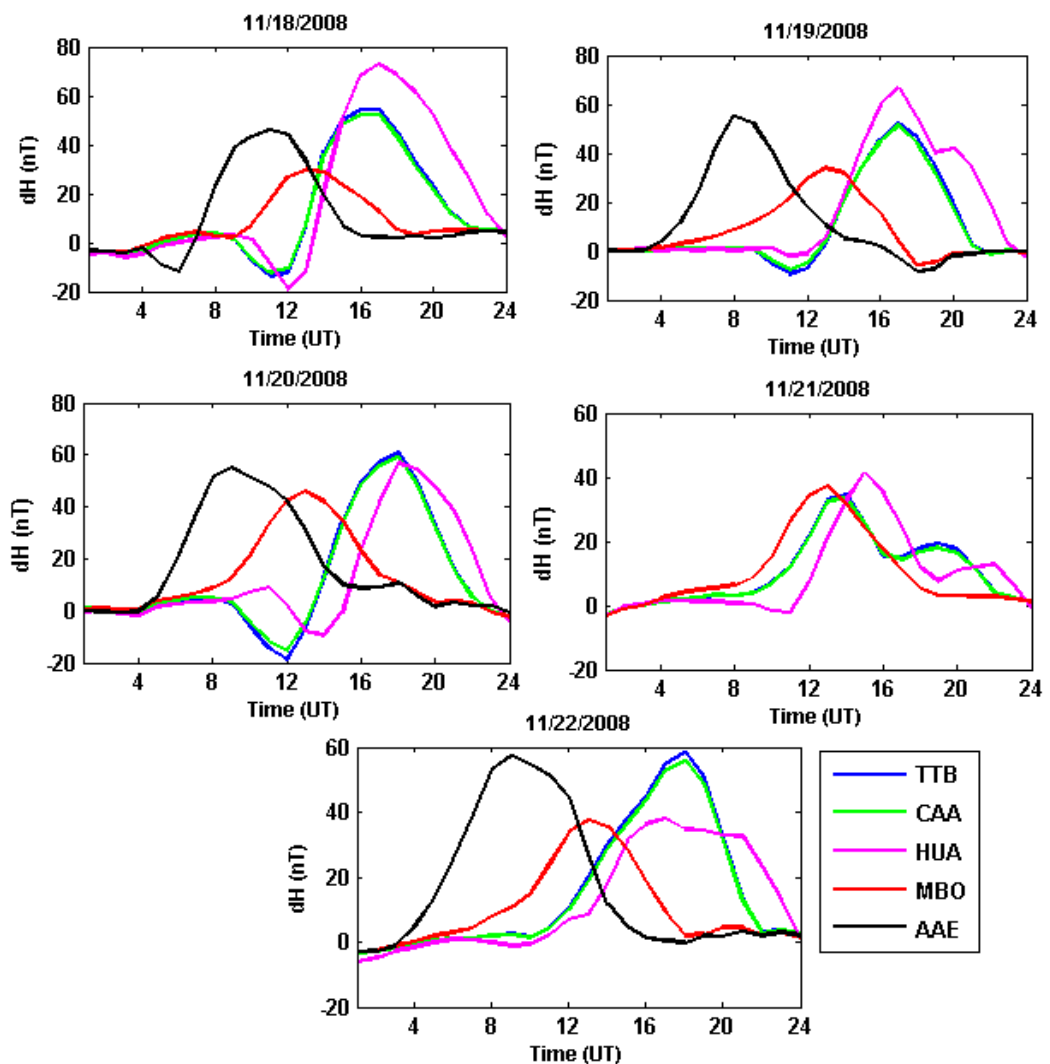

Figure 3 - Variations of the horizontal component of the geomagnetic field for the five quietest days. 

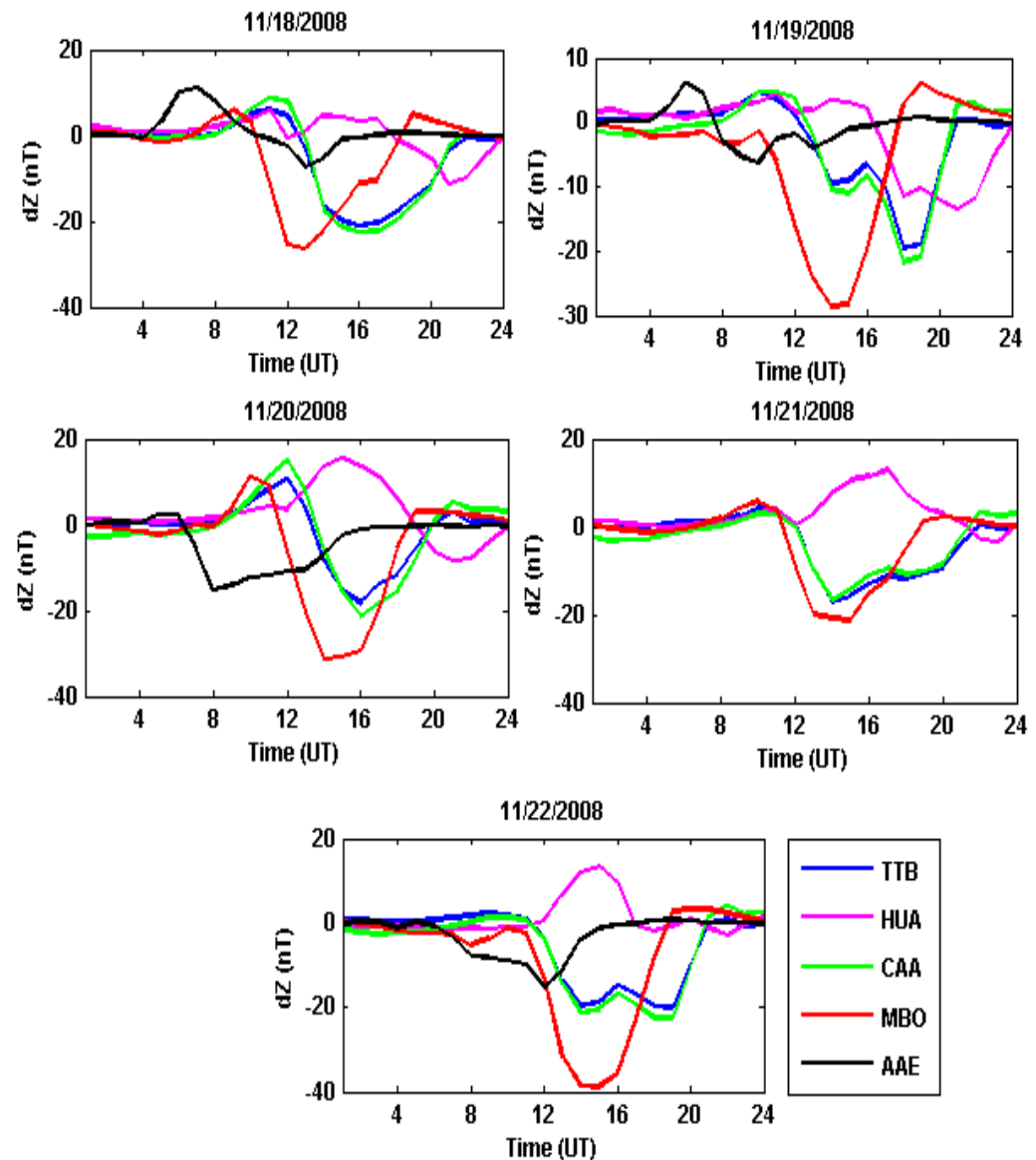

Figure 4 - Variations of the vertical component of the geomagnetic field for the five quietest days.

\section{Conclusion}

This study has yielded some interesting results which are in agreement with previously research works in the area. The results show that the amplitude $\mathrm{dH}$ in HUA station is higher than that in other stations used in this work. The morphology of the curves obtained for $\mathrm{H}$ and $\mathrm{Z}$ might be interpreted to be due to the Equatorial Electrojet (EEJ). Moreover, diurnal variations curves of TTB, CAA, HUA and $A A E$ indicated the presence of MCEJ. The curves present the same shape. However, a phase difference was observed. The diurnal variation of the $Z$ component displayed an opposite sign from the northern side of the dip equator to the southern side.

\section{Acknowledgements}

The authors are thankful to the National Observatory and Ministry of Science and Technology for the financial support. The data from the Rebom project is acknowledged. Also, the data from INTERMAGNET is acknowledged. The authors are especially thankful to the technicians Ronaldo M. Carvalho and Elisabeth C. Lima who worked on the Rebom project. 


\section{References}

Adimula, et al., 2011.Geomagnetic Field Variations from some Equatorial Electrojet Stations, Sun and Geosphere, 6(2): $45-49$.

Alex, S. and Mukherjee, S., 2001. Local time dependence of the equatorial counter electrojet effect in a narrow longitudinal belt, Earth, Planets and Space, 53, 11511161.

Chapman, S.,1951a. Some phenomena of the upper atmosphere, Proc. Phys. Soc. London, B, 64, 833-843.

Hamid, et al., 2014. Relationship between the equatorial electrojet and global $\mathrm{Sq}$ currents at the dip equator region, Earth, Planets and Space, 66: 146.

Obiekezie, T.N., 2012, Geomagnetic field variations at dip equatoriallatitudes of West Africa, International Journal of Physical Sciences, 7(36), pp. 5372-5377.

Obiekezie, et al., 2013, Day-to-Day Variability of $\mathrm{H}$ and Z Components of the Geomagnetic Field at African Longitudes, Hindawi Publishing Corporation, 2013.

Rabiu A. B. et al., 2007, Variability of equatorial ionosphere inferred from geomagnetic field measurements, Bull. Astr. Soc. India, 35, 607-618.

Yamazaki, Y., et al., 2011. An empirical model of the quiet daily geomagnetic field variation, Journal of Geophysical Research, 116, A103112. 